\title{
Role of Corticosteroids in Reducing Respiratory Morbidity in Neonates Delivered by Elective Cesarean Section before 39 Weeks
}

\author{
Arshad Khushdil1, Shehla Baqai², Madiha Ahmed² and Zeeshan Ahmed ${ }^{1}$
}

\begin{abstract}
Objective: To determine the effect of dexamethasone administration to women between 37 to 39 weeks of gestation on neonatal outcome in terms of respiratory morbidity and the need for NICU admission.

Study Design: An experimental study.

Place and Duration of Study: Department of Obstetrics and Department of Neonatology, Military Hospital, Rawalpindi, Pakistan, from February to July 2017.

Methodology: Women with singleton pregnancies, undergoing elective cesarean section between 37-39 weeks. Neonates were evaluated for any respiratory morbidity and need for NICU admission as well as need of mechanical ventilation, length of hospital stay and final outcome.

Results: Out of 535 patients, 240 (44.8\%) patients received steroid cover before their elective cesarean section (group 1). Two hundred and ninety-five (55.2\%) patients who did not receive steroid cover, were allocated group 2. Mean age of mothers in group 1 was $29.20 \pm 4.50$ years and in group 2 , it was $29.34 \pm 4.50$ years. The mean gestational ages were $37.56 \pm 0.66$ weeks and $38.11 \pm 0.79$ weeks in groups 1 and 2, respectively. In group 2, $14(4.74 \%)$ newborns developed transient tachypnea of newborn (TTN), which was higher than the newborns in group $1(04(1.66 \%), p=0.049)$. Also the number of neonates being admitted to NICU was greater in group 2 than in group 1 [23 $(7.79 \%)$ vs. $06(2.5 \%)$ respectively, $p=0.007]$. However, there was no statistically significant difference between the two groups with regard to final outcome, requirement for mechanical ventilation, length of hospital stay and APGAR scores at one and five minutes.

Conclusion: Steroid cover significantly reduced the risk of respiratory morbidity in babies delivered by elective cesarean section between 37-39 weeks.
\end{abstract}

Key Words: Corticosteroids, Elective C-section, Neonates, NICU.

\section{INTRODUCTION}

Over the last decade, rate of cesarean section (C-section) has increased worldwide. Almost $15-25 \%$ of all deliveries are by cesarean section in developed countries. ${ }^{1}$ A similar trend has been seen in the developing world with rates of $27.6 \%$ from Egypt and $21.7 \%$ from Pakistan. 2,3 According to WHO, C-section is effective in saving lives of mothers as well as neonates only if done for medical conditions, but at rates more than $10-15 \%$ there is no additional health benefit in terms of reducing maternal and neonatal mortality. ${ }^{4}$ The main reasons for increasing rates of $\mathrm{C}$-sections are different in different regions but mostly $\mathrm{C}$-sections are performed due to decreasing rends for TOLAC (trial of labour after caesarean section), elective cesarean for breech presentation and maternal request. 5

Department of Neonatologyl / Obstetrics and Gynaecology2, Military Hospital, Rawalpindi, Pakistan

Correspondence: Dr. Arshad Khushdil, Department of

Neonatology, Military Hospital, Rawalpindi, Pakistan

E-mail: drarshad104589@yahoo.com

Received: January 06, 2018; Accepted: July 12, 2018
As with any other surgery, C-section is associated with both neonatal and maternal complications. There is increased incidence of respiratory problems in neonates born via $\mathrm{C}$-section and the incidence increases in those who are born prematurely or via elective C-section before 39 weeks of gestation. The administration of corticosteroids to mother in pre-term labour has proven benefits to the neonate in terms of reduced respiratory morbidity mainly transient tachypnea of newborn (TTN) and respiratory distress syndrome (RDS). ${ }^{6}$ The Royal College of Obstetrics and Gynecology in 2010 started advocating the use of antenatal corticosteroids to mothers undergoing elective $\mathrm{C}$-section prior to 39 weeks of gestation, in order to reduce the neonatal respiratory morbidity. ${ }^{7}$ However, the evidence for such recommendation is questionable. Studies have shown no additional benefits of administering corticosteroids to mothers after 34 weeks. ${ }^{8}$

Very few studies have been conducted so far in Pakistan to see the effects of corticosteroids given to mothers undergoing elective C-sections before 39 weeks, on neonatal respiratory morbidity.

The aim of the present study was to determine the effects of antenatal corticosteroids given to the mothers undergoing elective $\mathrm{C}$-section on neonatal respiratory morbidity. 


\section{METHODOLOGY}

This was a non-randomised experimental study, conducted at Military Hospital, Rawalpindi, from February to July 2017 after obtaining approval from Hospital Ethical Committee. It included all women with singleton pregnancy, who underwent $\mathrm{C}$-section between 37 to 39 weeks gestation. However, women who had history of rupture of membranes for more than 18 hours, who had history of fever, urinary tract infection, chorioamnionitis, history of drug intake or any chronic medical illness were excluded from the study. All newborns of either gender were included in this study. However, twin babies, babies who had congenital heart lesions or any dysmorphic features, those with intrauterine growth restriction, and surgical conditions were excluded from the study.

The women who fulfilled the inclusion criteria were divided into two groups. Group 1 was the treatment group and received injection dexamethasone according to the recommended dose and duration i.e., $12 \mathrm{mg}$ intramuscularly 12 hours apart for a total of four doses; and group 2 was the control group which did not receive injection dexamethasone.

Data was collected from Hospital record sheets regarding age of the mother, obstetric history, gestational age, current pregnancy complications, any maternal medical illness, history of any drug use by mother and the indication for $\mathrm{C}$-section. Neonates were assessed after delivery for various parameters like APGAR scores at one and five minutes, birth weight, respiratory distress requiring oxygen administration, length of hospital stay, need for mechanical ventilation, neonatal intensive care unit (NICU) admission, and final outcome. Consultant neonatalogist decided whether the baby needs admission to NICU or not for respiratory morbidity.

Informed written consent was taken from parents of all babies. Data was analysed using SPSS version 20. Numerical data like gestational and maternal ages were expressed as mean and standard deviation. Qualitative data were expressed as frequencies and percentages. Chi-square test was used to determine the relationship between qualitative variables while independent sample t-test was used to compare the means of gestational ages of both groups. The $p$-value $<0.05$ was considered significant.

\section{RESULTS}

During the study period, 585 elective C-sections were performed, but 535 women met the inclusion criteria; $182(34.01 \%)$ C-sections were performed at 37 weeks, $269(50.28 .71 \%)$ at 38 weeks and $59(11.02 \%)$ at 39 weeks; whereas, 25 (4.67\%) C-sections were performed at 40 weeks gestation. Most common indication of $\mathrm{C}$-section was abdominal scar due to previous C-section.
There were 240 (44.8\%) women in group 1, and 295 $(55.2 \%)$ women in group 2. Mean age of mothers in group 1 was $29.20 \pm 4.50$ years and in group 2, it was $29.34 \pm 4.50$ years. The mean gestational ages were $37.56 \pm 0.66$ weeks and $38.11 \pm 0.79$ weeks in groups 1 and 2 , respectively (Table I).

In group 1, $128(53.33 \%)$ C-sections were performed at 37 weeks, $91(37.91 \%)$ were carried out at 38 weeks, $20(8.75 \%)$ were performed at 39 weeks of gestation while $1(0.42 \%)$ C-section was performed at 40 weeks gestation. In group 2, $54(18.30 \%)$ C-sections were performed at 37 weeks, $178(60.33 \%)$ at 38 weeks, $39(13.22 \%)$ at 39 weeks of gestation and $24(8.13 \%)$ C-section were performed at 40 weeks gestation.

In group 2 (control group), 14 (4.74\%) newborns developed transient tachypnea of newborn which was higher than the newborns in group $1(4,1.66 \%)$, p-value $=0.049$ ). The number of neonates being admitted to

Table I: Demographic characteristics of women and neonates in two groups.

\begin{tabular}{l|c|c|c}
\hline Variables & Group 1 & Group 2 & p-value \\
\hline Gestational age (weeks) & $37.56 \pm 0.66$ & $38.11 \pm 0.79$ & 0.000 \\
\hline Parity & $33(13.75 \%)$ & $26(8.81 \%)$ & 0.07 \\
$\quad$ Zero & $207(86.25 \%)$ & $269(91.19 \%)$ & \\
$\quad>$ zero & $163(67.91 \%)$ & $197(66.78 \%)$ & 0.780 \\
\hline $\begin{array}{l}\text { Maternal age (years) } \\
15-30\end{array}$ & $77(32.09 \%)$ & $98(33.22 \%)$ & \\
$>30$ & $03(1.25 \%)$ & $03(1.02 \%)$ & 0.255 \\
\hline Birth weight (kg) & $236(98.33 \%)$ & $286(96.95 \%)$ & \\
$\quad<2.5$ & $01(0.42 \%)$ & $06(2.03 \%)$ & \\
$2.5-4.0$ & $136(56.66 \%)$ & $164(55.59 \%)$ & 0.80 \\
$>4.0$ & $104(43.34 \%)$ & $131(44.40 \%)$ & \\
\hline Gender of neonates & & \\
Female &
\end{tabular}

Table II: Outcome of neonates in two groups.

\begin{tabular}{l|c|c|c}
\hline Variables & Group 1 & Group 2 & p-value \\
\hline $\begin{array}{l}\text { Respiratory morbidity } \\
\text { requiring oxygen }\end{array}$ & & & \\
$\begin{array}{l}\text { supplementation } \\
\text { Yes }\end{array}$ & $04(1.66 \%)$ & $14(4.74 \%)$ & 0.049 \\
No & $236(98.34 \%)$ & $281(95.26 \%)$ & \\
\hline NICU admission & & & \\
Yes & $06(2.5 \%)$ & $23(7.79 \%)$ & 0.007 \\
No & $234(97.5 \%)$ & $272(92.21 \%)$ & \\
\hline Ventilatory support & & & 0.163 \\
Yes & $01(0.41 \%)$ & $05(1.69 \%)$ & \\
No & $239(99.59 \%)$ & $290(98.31 \%)$ & \\
\hline Hospital stay (hours) & & & \multirow{2}{*}{0.154} \\
$<06$ & $233(97.08 \%)$ & $275(93.22 \%)$ & \\
$6-24$ & $3(1.25 \%)$ & $4(1.35 \%)$ & \\
$24-48$ & $1(0.41 \%)$ & $5(1.69 \%)$ & \\
$>48$ & $3(1.25 \%)$ & $11(3.72 \%)$ & \\
\hline Final outcome & $239(99.59 \%)$ & $294(99.66 \%)$ & 0.88 \\
Discharged & $01(0.41 \%)$ & $01(0.34 \%)$ & \\
Expired & & & \\
\hline
\end{tabular}


$\mathrm{NICU}$ was greater in group 2 than in group 1 [23 $(7.79 \%)$ vs. $6(2.5 \%)$ respectively, $p=0.007$ ] as shown in Table II. Of 29 neonates who were admitted to NICU, males were 16 and 13 were female babies and majority of the babies, were between 2.5 to $4.0 \mathrm{~kg}$ birth weight.

However, there was no statistically significant difference between the two groups with regard to final outcome, requirement for mechanical ventilation, length of hospital stay and APGAR scores at one and five minutes (Table II). One neonate in both groups died because of neonatal sepsis, rest all babies were discharged home. In both groups, maximum number of babies remained in NICU for less than six hours [233 $(97.08 \%)$ in group 1 vs. $275(93.22 \%)$ in group 2].

\section{DISCUSSION}

In the current study, the effects of administering corticosteroids to mothers who were planned to have elective C-section after 37 weeks gestation, were evaluated in terms of neonatal respiratory morbidity requiring oxygen supplementation and the requirement for admission to NICU. The study found that administering dexamethasone reduced the occurrence of respiratory morbidity and admission to NICU. However, there was no statistically significant difference on the APGAR scores at one and five minutes, length of hospital stay, requirement of mechanical ventilation and final outcome.

Using antenatal steroids after 37 weeks of gestation helps to reduce respiratory morbidity by different mechanisms. One is increasing the number and function of the sodium channels in the apical membrane of respiratory epithelium thereby increasing the reabsorption of the fluid from lungs. ${ }^{9}$ The other is increasing the responsiveness to catecholamines and thyroid hormones. 10

Elective C-section is associated with increased incidence of respiratory morbidity and subsequent hospital admission and hospital stay as compared to vaginal delivery and emergency $\mathrm{C}$-section. This leads to financial burden on the state as well as the individual in the form of expensive neonatal care, parental anxiety, separation of newborn from the mother and increased risk of neonatal morbidity secondary to NICU admission. All these problems warrant adoption of the strategies which can minimise the respiratory morbidity in those born via elective $\mathrm{C}$-section. One of the strategies that seems promising, is the administration of steroids to mothers undergoing elective C-section before 39 weeks of gestation as recommended by the American College of Obs and Gynae and Royal College of Obs and Gynae.7,11

Neonatal respiratory morbidity is increased by various risk factors including gender of the newborn, birth weight, type of anesthesia given to mother at the time of C-section, maternal medical conditions like premature rupture of membranes (PROM), maternal fever, and history of maternal medication use. ${ }^{12,13}$ But in this study, all those babies who were born to mothers with history of PROM and other medical disorders were excluded. All the C-sections were performed under spinal anesthesia. There was no statistically significant difference between the two treatment groups in our study as far as birth weight and gender of the neonates were concerned. Same results were shown by study conducted in Egypt. 14

This study revealed that there was statistically significant difference between the two groups with regard to respiratory morbidity and admission to NICU. The same results were shown by a study conducted by Nada et al. in 2015, which showed a reduction in the incidence of respiratory morbidity as well as NICU admission. ${ }^{15}$ Their results showed that the rate of respiratory morbidity in corticosteroid treated group was $1.3 \%$, while in control group it was $3.4 \%(p=0.014)$. In this study, it was $1.66 \%$ versus $4.74 \%(p=0.049)$ for the treatment and control groups, respectively. Similarly, their study showed rates of NICU admission in two groups at $2.8 \%$ and $12.7 \%$, respectively $(p=0.003)$. In this study, these were $2.5 \%$ and $7.79 \%$ for the treatment and control groups, respectively $(p=0.007)$. Same results were shown by study conducted by Stutchfield et al. which showed a reduction in NICU admission in the group who received antenatal corticosteroids. ${ }^{16}$ The study carried out by Hansen et al. has the same results in terms of reduced neonatal respiratory morbidity in the corticostriod treated group. ${ }^{17} \mathrm{~A}$ study conducted by Dileep et al. in Karachi also found that administration of corticosteroids to mothers undergoing elective C-section at term was associated with reduced NICU admission and respiratory morbidity. ${ }^{18}$

These results are also in agreement with a Cochrane systematic review, which stated that there was a reduction in NICU admission for babies whose mothers received antenatal corticosteroids. ${ }^{19}$ However, the same review did not find any statistically significant difference as far as the respiratory morbidity was concerned. The results of this study are in contrast to a study carried out by Hutchson, who showed that antenatal corticosteroids have no role in reducing the neonatal respiratory morbidity as well as NICU admission. ${ }^{20}$ However, according to Hutchson, if a large sample size is taken and the study is adequately powered then there might be a reduction in terms of respiratory morbidity and NICU admission.

This study revealed that there was no significant difference between the two groups in terms of need for mechanical ventilation, length of hospital stay, and the final outcome. These results were in agreement with studies performed by Nada et al., Dileep et al., and Sotiriadis et al.15,18,19 
The present study has certain limitations. The sample size is small, though it was the largest sample size for any such study conducted so far in Pakistan. Lack of long term follow-up of babies whose mothers received dexamethasone. It was a non-randomised trial. Hence, a randomised controlled trial with large sample size need to be carried out with long term follow-up in order to know the effects of corticosteroids on neonates.

\section{CONCLUSION}

Corticosteroids should be administered to women who are planned for elective C-section between 37 to 39 weeks of gestation in accordance with ACOG and RCOG guidelines. Hence, we recommend that delaying the elective C-section beyond 39 weeks of gestation or administering corticosteroids to those who are going to be planned for elective C-section between 37 to 39 weeks gestation in order to reduce the burden of neonatal intensive care units as well as reduce the parental anxiety and financial burden.

\section{REFERENCES}

1. Betrán AP, Merialdi $M$, Lauer JA, Bing-Shun W, Thomas J, Van Look $\mathrm{P}$, et al. Rates of caesarean section: analysis of global, regional and national estimates. Paediatr Perinat Epidemiol 2007; 21:98-113.

2. El-Zanaty F, Way AA. Egypt demographic and health survey. Cairo, Egypt: Ministry of Health and Population [Arab Republic of Egypt], National Population Council [Arab Republic of Egypt]; 2009.

3. Naeem M, Zia M, Islam U, Abbas SH, Khan A, Adil M, et al. Rate and indications of elective and emergency caesarean section: A study in a tertiary care hospital of peshawar. J Ayub Med Coll Abbottabad 2015; 27:151-4.

4. WHO Statement on Caesarean Section Rates; 2014.

5. Haider G, Zehra N. Frequency and indications of cesarean. Pak J Med Sci 2009; 25:791-6.

6. Marciniak B, Patro-Malysza J, Poniedzialek-Czajkowska E, Kimber-Trojnar Z, Leszczynska-Gorzelak B, Oleszczuk J. Glucocorticoids in pregnancy. Curr Pharm Biotechnol 2011; 12:750-7.

7. Royal College of Obstetricians \& Gynaecologists [Internet]. Antenatal corticosteroids to reduce neonatal morbidity and mortality. London: RCOG; 2010. (Greentop Guideline no. 7) [cited 2015 Dec 27]. Available from: https://www.rcog.org.uk/ globalassets/ documents/guidelines/gtg_7.pdf
8. Kamath-Rayne BD, De Franco EA, Marcotte MP. Antenatal steroids for treatment of fetal lung immaturity after 34 weeks of gestation: An evaluation of neonatal outcomes. Obstet Gynecol 2012; 119:909-16.

9. Ahmed MR, Ali W, Ahmed S, Mohammed TY, Refaat M, Ali W, et al. Antenatal steroids at 37 weeks, does it reduce neonatal respiratory morbidity? A randomized trial. J Matern Fetal Neonatal Med 2015; 28:1486-90.

10. Jain L, Dudell GG. Respiratory transition in infants delivered by cesarean section. Semin Perinatol 2006; 30:296-304.

11. Clinical Practice Guidelines for Perinatal Care. American College of Obstetrics and Gynaecology [online] [cited 2017 Dec 5]; Available from URL: https://www.wellcare.com/wcassets/ corporate/assets/ny_medicaid_pem_cpg-erinatalcare.pdf.

12. van den Berg A, van Elburg RM, van Geijn HP, Fetter WP. Neonatal respiratory morbidity following elective caesarean section in term infants. A 5-year retrospective study and a review of the literature. Eur J Obstet Gynecol Reprod Biol 2001; 98:9-13.

13. Gerten KA, Coonrod DV, Bay RC, Chambliss LR. Cesarean delivery and respiratory distress syndrome: does labor make a difference? Am J Obstet Gynecol 2005; 193:1061-4.

14. Salem MN, Abbas AM, Ashry M. Dexamethasone for the prevention of neonatal respiratory morbidity before elective cesarean section at term. Proc Obstet Gynecol 2016; 6:2.

15. Nada AM, Shafeek MM, El Maraghy MA, Nageeb AH, Salah EI Din AS, Awad MH. Antenatal corticosteroid administration before elective caesarean section at term to prevent neonatal respiratory morbidity: a randomized controlled trial. Eur $J$ Obstet Gynecol Reprod Biol 2016; 199:88-91.

16. Stutchfield PR, Whittaker R, Russell I. Antenatal betamethasone and incidence of neonatal respiratory distress after elective caesarean section; pragmatic randomised trial. BMJ 2005; 331:662-4.

17. Hansen AK, Wisborg K, Uldbjerg N, Henriksen TB. Risk of respiratory morbidity in term infants delivered by elective caesarean section: cohort study. BMJ 2008; 336:85.

18. Dileep A, Khan NB, Sheikh SS. Comparing neonatal respiratory morbidity in neonates delivered at term by elective Caesarean section with and without dexamethasone: retrospective cohort study. J Pak Med Assoc. 2015; 65:607-11.

19. Sotiriadis A, Makrydimas G, Papatheodorou S, Ioannidis JP. Corticosteroids for preventing neonatal respiratory morbidity after elective caesarean section at term. Cochrane Database Syst Rev 2009; 4:CD006614.

20. Hutchon DJR. A clearer explanation of no benefit for steroids. BMJ 2005 (e-Letter). 